\title{
ACTIVIDAD IN VITRO DE LOS VENENOS DE Lachesis muta Y Bothrops atrox SOBRE LA VIABILIDAD Y DESARROLLO EMBRIONARIO DE LOS HUEVOS DE Ascaris suum
}

\section{IN VITRO ACTIVITY OF Lachesis muta AND Bothrops atrox VENOMS ON THE VIABILITY AND EMBRIONARY DEVELOPMENT OF Ascaris suum EGGS}

\author{
Claudia Paredes ${ }^{1}$, Inés Gárate ${ }^{1}$ y Armando Yarlequé ${ }^{2}$
}

\section{RESUMEN}

Los venenos de serpientes son concentrados polienzimáticos cuya actividad biológica sobre algunas bacterias y protozoos ha sico comprobada. El objetivo principal del presente trabajo fue estudiar la actividad in vitro de los venenos totales de las serpientes Lachesis muta y Bothrops atrox sobre la viabilidad y el desarrollo embricnario de los huevos de Ascaris suum.

Se emplearon los venenos totales en concentraciones de 2, 4,8 y $16 \mathrm{mg} / \mathrm{mL}$ sobre huevos no embrionados y larvados in vitro.

Se comparó la actividad de los venenos con la de otras sustancias como el hipoclorito de sodio al $5,25 \%$, Albendazol (solución comercial) y solución salina.

Ambos venenos, en concentraciones de 4,8 y $16 \mathrm{mg} / \mathrm{mL}$, inhibieron la blastulación de estos huevos hasta el sexto día de incubación; en cambio en concentración de $2 \mathrm{mg} / \mathrm{mL}$ la inhibición se dio hasta el cuarto día. Posteriormente iniciaron un proceso de embrionación aparentemente normal hasta la formación del estadio infectante. El veneno de $B$. atrox fue el que presentó el mayor efecto inhibitorio en concentración de $16 \mathrm{mg} / \mathrm{mL}$. El hipcclorito de sodio destruyó el $100 \%$ de los huevos, mientras el albendazol ocasionó que los huevos iniciaran un proceso de segmentación anormal que originó su degeneración.

Se concluye que los venenos de $L$. muta y $B$. atrox muestran actividad inhibitoria al inicio de la blastulación de los huevos de $A$. suum y no ejercen ningún efecto en los huevos larvados.

Palabras claves: Veneno, serpiente, Ascaris, parásitos.

\section{SUMMARY}

Snake venoms are polierizymatic concentrated whose biological activity on some bacteria and protozoa has been proven. To study the in vitro activity of Lachesis muta and Bothrops atrox venoms on the viability and the development of Ascaris suum eggs is the main objective of this work.

The venoms were employed in non embryonated and in vitro embryonated eggs of Ascaris suum at different concentrations $(2,4,8,16 \mathrm{mg} / \mathrm{mL})$. The activity of the venoms in the eggs and other substances like 5,25\% scdium hypochlorite, Albendazol (commercial solution) and sodium chloride was compared.

Both venoms, at $2,4,8,16 \mathrm{mg} / \mathrm{mL}$ concentrations, inhibited segmentation of these eggs until the sixth day of incubation, when they began an apparently normal embryonation process that ended in the formation of the infective stage. The most effective inhibitory concentration was $16 \mathrm{mg} / \mathrm{mL}$ of $B$. atrox venom. The sodium hypochlorite destroyed $100 \%$ of eggs, while Albendazol produced abnormal segmentation process on them and their degeneration.

We conclude that $L$. muta and $B$. atrox venoms have an inhibitory activity at the begining of segmentation in Ascaris suum eggs and they do not cause any effect on embryonated ones.

Key words: Venoms, snake, Ascaris, parasites.

' Laboratorio de Parasitología Humana y Animal.

${ }^{2}$ Laboratorio de Biología Molecular. Fac. Ciencias Biológicas. UNMSM

Dirección: Laboratorio de Parasitología Humana y animal. Facultad de Ciencias Biológicas. UNMSM,

Av.Venezuela sin número, Lima. E mail: d190017@unmsm.edu.pe, paredesesq@latinmail.com 


\section{INTRODUCCIÓN}

La ascariosis es una infección parasitaria muy común en el hombre, la cual afecta aproximadamente al $25 \%$ de la poblaciôn mundiai, principalmente en países en vías de desarrollo (Lumbreras y Náquira, 1985). Es ocasionada por el geohelminto Ascaris lumbricoides, especie que posee una estrecha relación con Ascaris suum, que infecta al cerdo (Schmidt y Roberts, 1984).

En el Perú es posible que el $14,5 \%$ de la población esté infectada con esta parasitosis; Lumbreras y Náquira reportaron en 1985 un 75\% de nin̄os infectados en las regiones $R$ upa Rupa y Omagua.

Una de las razones que hace difícil controlar este parásito es la extraordinaria resistencia del huevo; pueden embrionar con éxito en soluciones al $50 \%$ de ácido clorhídrico, nítrico y sulfúrico (Schmidt y Roberts, 1984). Miranda (1961) señaló que pueden encontrarse embriones vivos en los huevos de Ascaris lumbricoides contenidos en heces humanas conservadas varios meses en formol.

I a gravedad del problema de la ascariosis en nuestro país ha llevado a la búsqueda de nuevas drogas antiparasitarias. Estudiando los venenos de serpientes, se ha comprobado que algunos de sus componentes tienen actividad biológica; se ha demostrado que poseen propiedades antibacterianas y que ejercen un efecto inhibitorio en algunos parásitos unicelulares (Skarnes, 1970; Bucher, 1971; Stiles et al., 1991; Fernández Gómez et al., 1994; Cisneros, 1996; Yarlequé et al., 1996).

En este trabajo se ha evaluado la actividad in vitro de los venenos totales de las serpientes Lachesis muta y Bothrops atrox en los huevos larvados y no embrionados de Ascaris suum; asi mismo se ha comparado la actividad de estos venenos con la de otras sustancias ovicidas, tales como el albendazol e hipoclorito de sodio.

\section{MATERIAL Y MÉTODOS}

\author{
Obtención de los parásitos y extracción \\ de los huevos
}

Se eligió al camal de Yerbateros, ubicado en el distrito de El Agustino, en Lima, como lugar de muestreo. Se seleccionaron hembras vivas de Ascaris suum, las que fueron colocadas en frascos de vidrio con tapa que contenían suero fisiológico. Los parásitos fueron transportados al laboratorio inmediatamente (Miranda, 1961).

En el laboratorio se midió la longitud de cada parásito, y se seleccionó las hembras adultas (OMS, 1967). Se disectó $2 \mathrm{~cm}$ de la parte terminal de los úteros. Se retiró la masa de huevos y fue colocada en frascos viales que contenían $3 \mathrm{~mL}$ de suero fisiológico. Se empleó un frasco para cada parásito.

Se tomó una pequeña porción de los huevos de cada frasco y se observó al microscopio de luz las características morfológicas y el estadio de maduración.

Embrionación de los huevos en condiciones normales

Para disgregar los huevos se utilizó la técnica descrita por Fairbairn y recopilada por Mac Innis y Vogue (1970). Esta técnica consiste en añadir $\mathrm{NaOH} 0,5 \mathrm{~N}$ a una masa de huevos y agitar empleando un agitador magnético; como resultado los huevos pierden la cubierta externa uterina. Nosotros realizamos una modificación de la técnica: empleamos un vórtex en lugar del agitador magnético, y de esta manera pudimos obtener huevos disgregados que no perdieron las cubiertas; éstas se perdieron únicamente en huevos con cubierta externa laxa.

Se colocó 20000 huevos in cada uno de cinco frascos viales transparentes y se completó el volumen a $4 \mathrm{~mL}$ con solución salina neutra que contenía formol al $2 \%$. Los frascos se incubaron en la estufa a $30^{\circ} \mathrm{C}$ 
(Fairbairn, 1970).

Con la ayuda de un capilar de vidrio, se cogió una alícuota de la suspensión de huevos y se observaron al microscopio 50 huevos elegidos al azar por vez. Las observaciones se realizaron cada dos días hasta la formación de larvas $\mathrm{L}_{2}$ en el interior de los huevos.

\section{Efecto de los venenos frente a huevos no embrionados}

Los venenos fueron conservados en congelación y las diluciones preparadas $15 \mathrm{mi}$ nutos antes de iniciar los ensayos. Se colocó cada dilución de los venenos y los controles en frascos viales en un volumen de $4 \mathrm{~mL}$, y se agregaron en cada uno de ellos aproximadamente 20000 huevos contenidos en $0,1 \mathrm{~mL}$ de solución salina. Cada ensayo se realizó por duplicado (García, 1989). Los resultados se expresaron en función de los promedios.

Los controles empleados fueron hipoclorito de sodio al 5,25\% y solución salina al $0,85 \%$. Así mismo se evaluó la actividad del albendazol in vitro (Elliot, 1994). Cada ensayo se realizó por duplicado.

La evolución de los huevos fue observada al microscopio de luz cada dos días, hasta la formación del estadio infectante.

\section{Actividad de los venenos en los huevos larvados}

Los huevos de Ascaris suum fueron cuantificados e incubados siguiendo los pasos descritos anteriormente. Transcurridos veinte días del periodo de incubación, se evaluó la viabilidad de las larvas en el interior de los huevos induciendo su motilidad por luz tenue (OMS, 1967). Se colocó 20000 huevos en frascos de vidrio y se adicionaron las soluciones de venenos y los controles respectivos por duplicado.

Se evaluó la actividad de las muestras problema transcurridas $2,24,48$ y 72 horas. Los resultados se expresaron en función de los promedios.

\section{RESULTADOS}

Características iniciales de los huevos en estudio

Un $66 \%$ de las hembras evaluadas poseía huevos fértiles, y la estructura de la cubierta externa de los huevos fue variada: el $18,75 \%$ presentó una cubierta bien definida, el $15,6 \%$ cubierta externa delgada, el $25 \%$ la presentó laxa y el $6,25 \%$ carecía de ella. No se observó correlación entre el estado de fertilidad de los huevos ni las características de su cubierta externa y la longitud de las hembras de este parásito.

El tipo de cubierta laxa se degradó fácilmente con $\mathrm{NaOH}$ al 0,5 N. La pérdida de la cubierta externa no alteró la estructura oval del huevo ni su proceso normal de embrionación,

\section{Actividad de los venenos en los huevos larvados}

Dos horas después de iniciado este ensayo, el $100 \%$ de los huevos enfrentados a la acción del hipoclorito de sodio perdió la cubierta proteica.

Transcurridas 24 horas, se observó que la concentración de $16 \mathrm{mg} / \mathrm{mL}$ de ambos venenos inhibió en su totalidad la presencia de bacterias en el medio; menores concentraciones no produjeron el mismo efecto. Con el hopoclorito de sodio, en el $36 \%$ de los huevos las cubiertas perdieron rigidez y su estructura característica, tomaron apariencia elongada o con una deformación a manera de bulbo, con la consiguiente ruptura del huevo y evaginación de la larva; en el $40 \%$ de los huevos no se observaron alteraciones morfológicas. El 14\% de los huevos tenía larvas móviles en el interior aun cuando presentaron alguna alteración estructural.

Transcurridas cuarenta y ocho horas, en los 


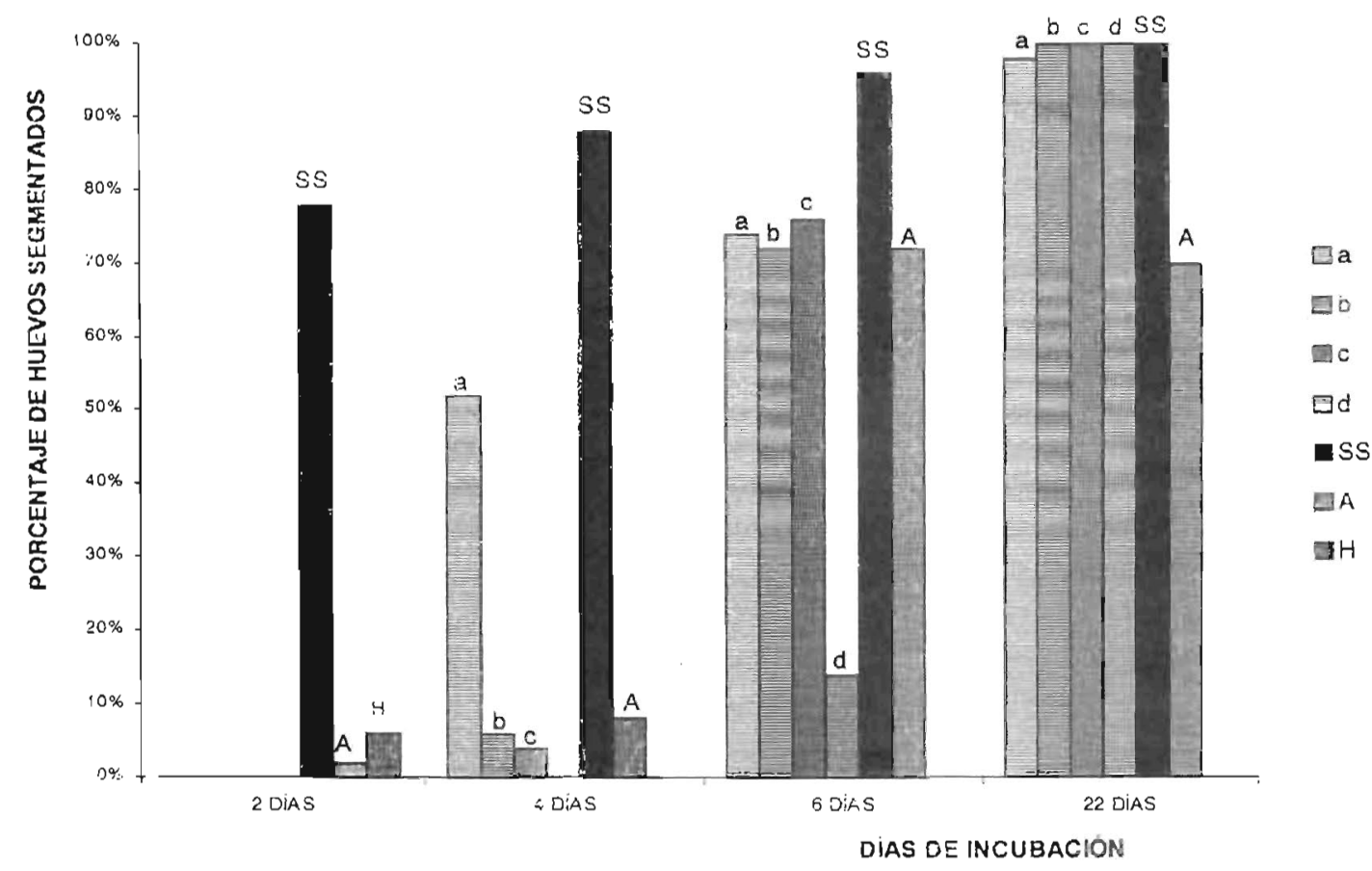

Figura 1. Efecto del veneno de B. atrox $(\mathrm{a}=2 \mathrm{mg} / \mathrm{mL}, b=4 \mathrm{mg} / \mathrm{mL}, \mathrm{c}=8 \mathrm{mg} / \mathrm{mL}$ y $\mathrm{d}=16 \mathrm{mg}$ / $\mathrm{mL}$ ) y de solución salina (SS); aljendazol (A) e hipoclorito de sodio (H) sobre el proceso de embrionación de los huevos de Ascaris suum.

viales que contenían las mayores concentraciones de venenos empezaron a aparecer bacterias en el medic.

Anl transcurrir setenta $y$ dos noras, el hipoclorito de sodio destruyó el $100 \%$ de los huevos y en el medio pudo obsarvarse sólo los restos de sus cubiertas. Durante las observaciones se apreció que ni los venenos ni i albendazol produjeron efecio alguno en los huevos.

\section{Efecto de los venenos en huevos no embrionados}

Al segundo día de incubación, se observó la inhibición total del desarrollo de ios huevos colocados a diferentes concentraciones de venenos de Lachesis muta y Bothrops atrox, con excepción de los huevos colocados en los viales que contenían la menor concentración del veneno de L. muta. Contrastando con el efecto de los venenos, en solución salina, el $78 \%$ de los huevos comenzó a desarrollar, e incluso se pudo observar huevos con cuatro células. El albendazol detuvo el desarrollo embrionario en casi la totahidad de los huevos, y sólo en un $2 \%$ se pudo apreciar dos blastómeros. Bajo el efecto del hipoclorito de sodio, el 64\% de los huevos fueron destruidos, un $2 \%$ logró desarrollar a huevos bipartidos, mientras un $4 \%$ lo hizo a huevos con cuatro células (Fig. 1 y 2 )

Al cuarto día, en el $6 \%$ de los ruevos en albendazol se formaron estructuras a manera de mórula, sin embargo la división de las células no obedeció al comportamiento normal; las células se asemejaban a pequeñas vesículas de diferente tamaño que diferían de la mórula característica formada por células simétricas. El 1.00\% de los huevos fueron destruidos bajo el efecto del hipoclorito de sodio.

Los huevos, en todos los viales con venenos, iniciaron el proceso de segmentación aparentemente normal a partir del sexto día de incubación hasta la formación del estadio 


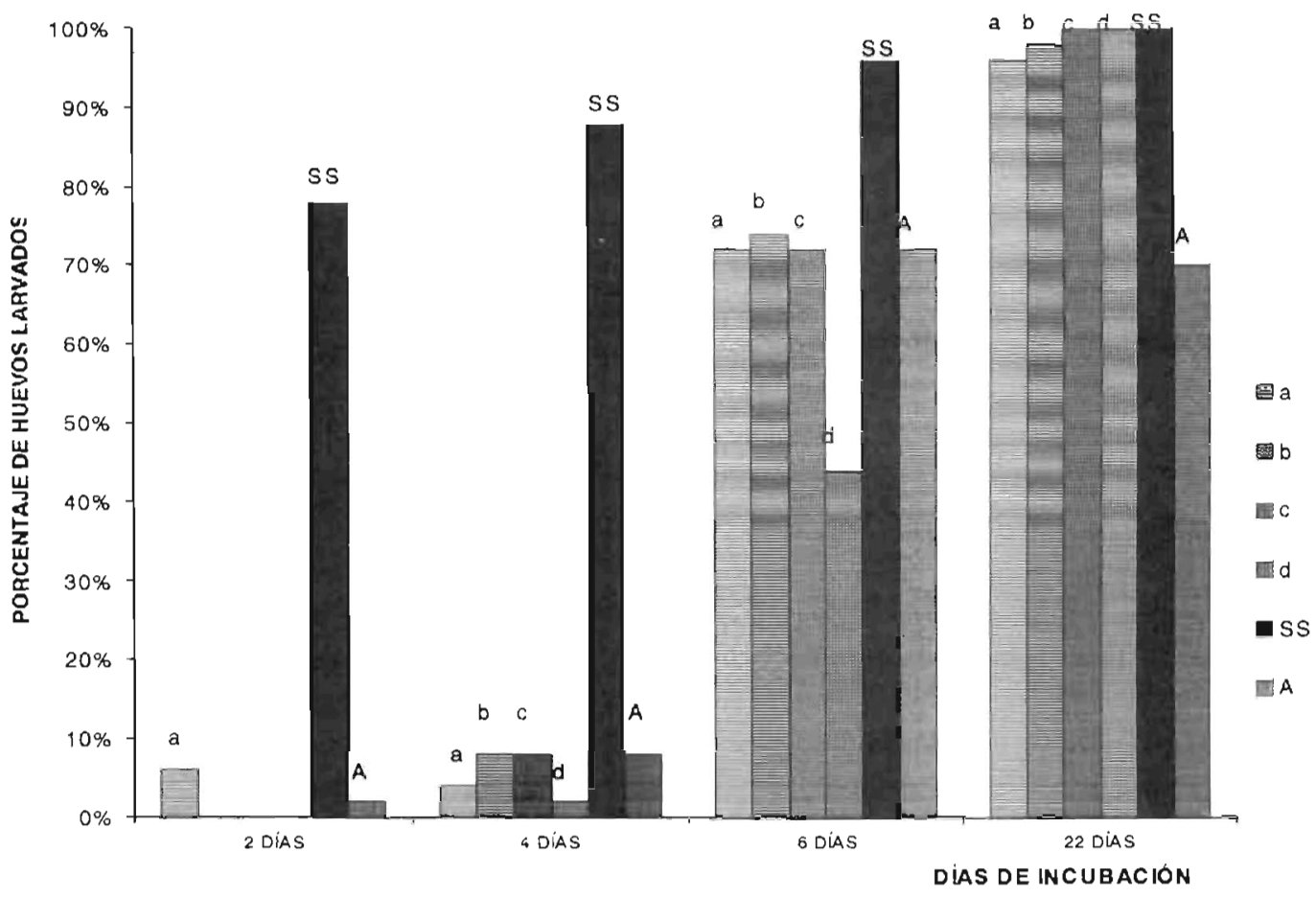

Figura 2. Efecto del veneno de L. muta $(a=2 \mathrm{mg} / \mathrm{mL}, b=4 \mathrm{mg} / \mathrm{mL}, c=8 \mathrm{mg} / \mathrm{mL}$ y $\mathrm{d}=16 \mathrm{mg} /$ $\mathrm{mL}$ ) y de solución salina (SS); albendazol (A) e hipoclorito de sodio (H) sobre el proceso de embrionación de los huevos de Ascaris suum.

infectante $L_{2}$ (Figuras 1 y 2 ).

A medida que transcurrieron los días, las larvas fueron disminuyendo la frecuencia de sus movimientos

\section{DISCUSIÓN}

En el presente trabajo se cemuestra que los venenos de las serpientes $L$. muta y $B$. atrox producen un retardo del desarrollo embrionario de los huevos de $A$. suum, mediante una inhibición temporal en la primera etapa del desarrollo. No se puede determinar en función de los resultados obtenidos qué ocasionó dicha inhibición; se presume que se debió al efecto individual o sinérgico de los componentes de estos venenos, entre los que encontramos un factor lítico directo constituido por proteínas de bajo peso molecular que - se ha comprobado- rompen los fosfolípidos de membranas de las bacterias (Aloof-Hirsch et al., 1968), así como de algunas enzimas contenidas en ellos, entre las que encontramos endopeptidasas, L aminooxidasas, fosfolipasas, nucleasas y toxinas (Figuras 1, 2,3 y 4 ).

Las cubiertas de los huevos de $A$. suum enfrentados a los venenos se mantuvieron aparentemente sin alteraciones morfológicas, lo que lleva a pensar que los venenos ejercieron un efecto inhibitorio indirecto análogo a los efectos que se ha demostrado frente a otros organismos vivos; Stiles (1991) demostró que el efecto bactericida de la $\mathrm{L}$ amino oxidasa de la serpiente australiana Pseudechis australis actúa ocasionando la desaminación oxidativa de los aminoácidos, generando $\mathrm{H}_{2} \mathrm{O}_{2}$ sustancia letal para algunos grupos microbianos; esta enzima no es hidrolítica, no causa necrosis de tejidos. Fernández Gómez et al. (1994) demostraron que el veneno total de la serpiente Cerastes cerastes menoscaba la síntesis de ácidos nucleicos de algunos estadios de los protozoos parásitos Trypanosoma cruzi y Leishmania sp., lo que inhibe su crecimiento. 


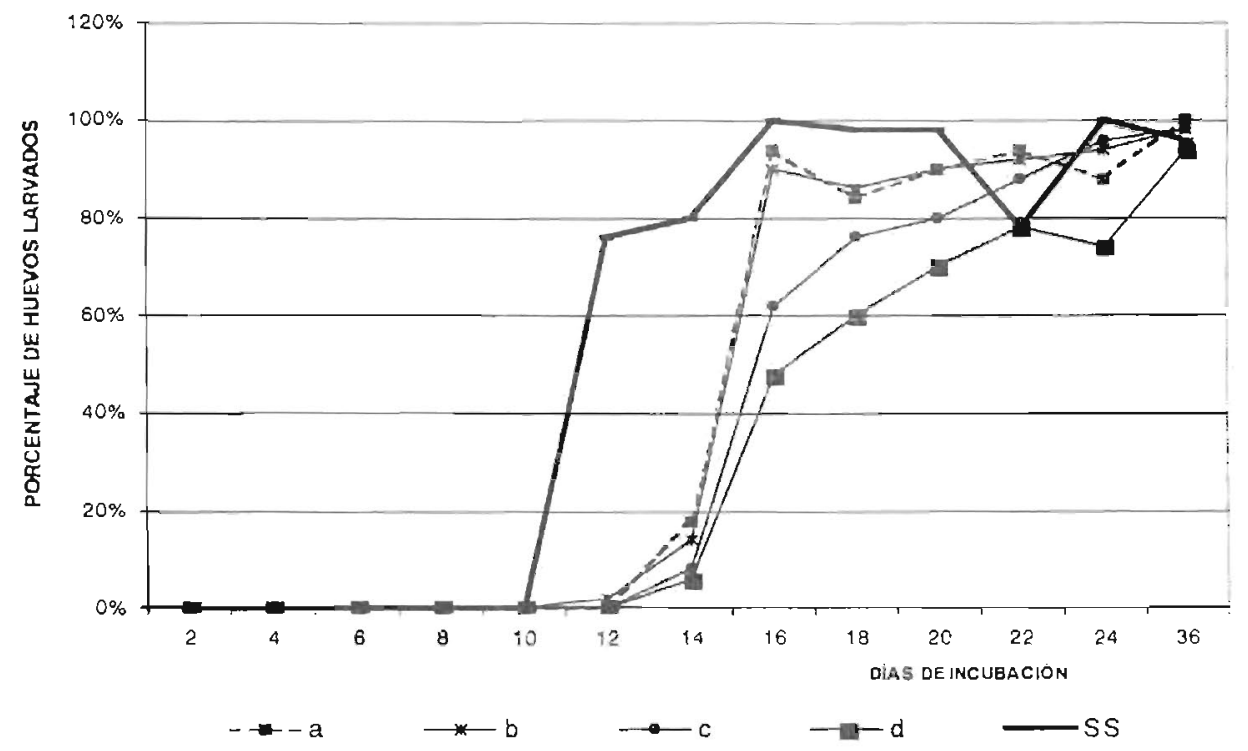

Figura 3. Formación de los huevos larvados de A. suumbajo el efecto del veneno de B. atrox ( $a=2 \mathrm{mg} / \mathrm{mL}, b=4 \mathrm{mg} / \mathrm{m}:-, c=8 \mathrm{mg} / \mathrm{mL}$ y d $=16 \mathrm{mg} / \mathrm{mL}$ ) y solución salina (SS).

La ausencia de bacterias en las mayores concentraciones de los venenos utilizados en este estudio se explicaría por la acción la Laminoácido oxidasa reportada para estos venenos en el laboratorio de Biología molecular de la Universidad Nacional Mayor de San Marcos. La enzima aislada de Lachesis muta, Bothrops atrox y Bothrops pictus mostró una potente acción inhibitoria del crecimiento de las bacterias Escherichia coli Staphylococcus aureus y Vibrio cholerae (Yarlequé, et al. 1996).

La posterior observación de bacterias podría haberse debido a la pérdida de estabilidad de dichos componentes, lo cual explicaría también que el proceso de segmentación de los huevos de $A$. suum se restableciese al sexto día de incubación (Figuras 1 y 2 ).

Durante los primeros días, la inhibición del desarrollo embrionario en los huevos fue directamente proporcional a la concentración de veneno empleada; esta relación directa no se mantuvo con el veneno de L. muta desde los diez días de incubación hasta el final del periodo; en cambio los huevos enfrentados al veneno de $B$. atrox mantuvieron la proporción hasta el final del proceso, lo cual nos indica que este último veneno fue más estable ( $\mathrm{Fi}$ gura 3 y 4 ).

Numerosos investigadores han escrito sobre la extrema resistencia de los huevos de Ascaris sp. (Rogers W., 1956; Lehmensick, 1960; Bird, 1971; Juris, 1995). En nuestro medio, Miranda (1961) atribuyó la resistencia de estos huevor, a elevadas concentraciones de formol a la complejidad de sus cubiertas. Rogers (1956) y Kunert (1992) coincidieron en que esta característica se debe a la cubierta ascarósida.

Este trabajo es una evidencia de la extrema resistencia de los huevos de $A$. suum, ya que estos lograron evolucionar al estadio infectante y resistir el efecto de complejos polienzimáticos, como son los venenos de las serpientes L. muta y B. atrox. En contraste, el hipoclorito de sodio ejerció un efecto corrosivo en las cubiertas de los huevos de este parásito, el cual fue visible desde el primer día de observación, pero sólo se pudo destruir el total de los huevos después de una exposición prolongada de setenta y dos horas. No obstante, durante las primeras veinticuatro horas 


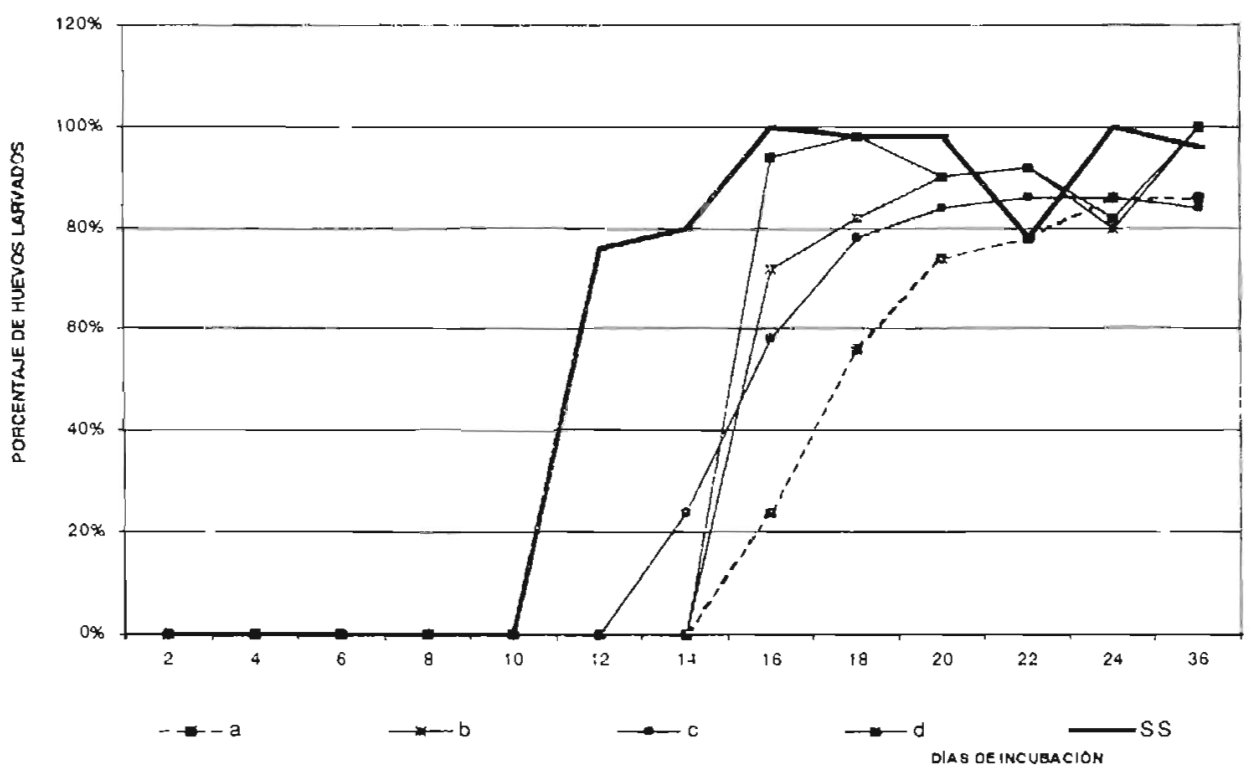

Figura 4. Formación de los huevos larvados de $A$. suum (Veneno de L. muta, solución salina hipoclorito y albendazol).

los embriones mostraron gran resistencia; prueba de ello fue la presencia de larvas nóviles en el interior de los huevos tal como se describió anteriormente.

En un trabajo realizado sobre la viabilidad de los huevos de Ascaris lumbriocoides después de un tratamiento con drogas antihelmínticas (levamisol, cambendazol, pamoato de pyrantel, mebendazol, thiabendazol y praziquantel), sólo una de ellas, el thiabendazol, eliminó el $100 \%$ de los huevos (Massara, 1991). En nuestro caso se obtuvo un $100 \%$ de eficacia con el Albendazol in vitro; su efecto no fue corrosivo, actuó degenerando y deteniendo el proceso de embrionación normal de los huevos (Figura 1 y 2), sin embargo no se observó efecto alguno en los huevos larvados. La inhibición generada por este antihelmíntico fue diferente de la ocasionada por los venenos de serpientes, ya que con ellos no se observó alteraciones celulares.

Los huevos recién extraídos del útero de las hembras se hallaron adheridos en forma de paquetes; según Miranda (1978), la membrana mamelonada ocasiona dicha adheren- cia y sólo perdiéndola los huevos pueden ser disgregados. No compartimos esta opinión, ya que en este trabajo se demuestra que se puede obtener una solución homogénea con huevos dispersos que conservaron dicha membrana.

Peter Darben (1997) menciona que los huevos fértiles de Ascaris lumbricoides pueden carecer de cubierta mamelonada y desarrollar normalmente; lo mismo es sostenido por otros autores como Miranda, R., 1978 y Miranda, H., 1961. Coincidimos con estas afirmaciones, pues la ausencia o las alteraciones morfológicas de la cubierta externa no alteraron el proceso de embrionación del huevo de Ascaris suum.

Miranda (1978) señaló que la pérdida de la cubierta mamelonada externa y la capa media transparente - como denomina él a la cubierta quitinosa - no alteran el embrión de Ascaris suum. En función de los resultados obtenidos discrepamos de lo sostenido por este autor, esto es, que los huevos carentes de cubierta externa no perdieron rigidez; se infiere que la perdida de su estructura oval caracteŕstica y deformación fue ocasionada por el debilitamiento de la cubierta quitinosa por acción del hipoclorito de sodio, pues su ruptura 
originaría la rápida degeneración de la cubierta lipídica, la que es soluble en todos los solventes comunes de grasas (Rogers, 1956). Esta conclusión concuerda con Fetterer (1993), quien sostiene que la cubierta quitinosa provee protección mecánica al huevo y preserva su estabilidad estructurai.

En solución salina más formol a! $2 \%$, a temperatura de $30^{\circ} \mathrm{C}$, casi la totalidad de los huevos evolucionan normalmente y en ausencia de bacterias, nuestros resultados contrastados con los de Miranda (1978) nos permiten considerar que el medio y la temperatura empleados en este ensayo son apropiados para la embrionación experimental de los huevos de Ascaris suum.

\section{CONCLUSIONES}

Después del análisis de los resultados obtenidos en esta investigación podemos arribar a las siguientes conclusiones:

1. El veneno de Bothrops atrox en concentraciones de $2,4,8$ y $16 \mathrm{mg} / \mathrm{mL}$ y el de Lachesis muta en 4, 8 y $16 \mathrm{mg} / \mathrm{mL}$, inhiben temporalmente, en un $100 \%$, el inicio de la blastulación de Ascaris suum.

2. El veneno de $B$. atrox muestra mayor estabilidad y ejerce una inhibición temporal ligeramente mayor que el veneno de Lachesis muta. El veneno de $B$. atrox en concentración de $16 \mathrm{mg} / \mathrm{mL}$ tuvo una acción inhibitoria más efectiva.

3. Los huevos embrionados de A. suum son resistentes a la acción de los venenos de las serpientes en estudio; dichos venenos no ocasionan alteraciones morfológicas visibles en lás cubiertas ni afectan la motilidad de las larvas.

4. El hipoclorito de sodio destruye las cubiertas de los huevos embrionados y no embrionados de Ascaris suum. En ambos casos se requiere una exposición prolongada de más de dos días para observarlos completamente destruidos

5. En presencia del albendazol, los hue- vos de $A$. suum inician un proceso de segmentación anormal que origina su degeneración. 6. La adición de soluciones de venenos ofídicos produjo también la inhibición del crecimiento bacteriano en torno a los huevos de Ascaris suum.

\section{LITERATURA CITADA}

Aloof-Hirsch, S.; A. Devries y A. Berger. 1968. The direct litic factor of cobra venom; purification and characterization biochem. Biophis. Acta 154:53-60.

Bird, A.F., 1971. The Structure of Nematodes. Edit Academic Press. New York,

Bücher, W., 1971. Venomous animals and their venoms, Academic Press, New York.

Cisneros, Y., 1996. Características bioquímicas de una proteína antibacteriana aislada del veneno de Lachesis muta (Shushupe). Tesis para optar el título profesional de Bíblogo. UNMSM, Lima, Penú.

Darben, P., 1997. Desarrollo de un tratamiento ovicida frente a A. lumbrricoides pag web:darben/ aboutdar.htm.

Elliot, A., 1994. Introducción a la Parasitología Médica del Perú. Edit. Martegraf, 3. ${ }^{\text {a }}$ ed. Instituto de Medicina Tropical Daniel A. Carrión. UNMSM, Lima, Perú

Fairbaim, D., 1970 Physiological hatching of Ascaris lumbricoides eggs. In MAC INNIS, A. and VOGUE. 1970. Experiments and techniques in Parasitology W. N. Freeman and Co. San Francisco, pp. 21-23.

Fernández Gómez, R.; H. Zerrouk; F. Sebti; M. Loyens; A. Benslimaney M. Ouaissi. 1994. Growth inhibition of Trypanosoma cruzi and Leishmania donovani infantum by different snake venoms: Preliminary identification of proteins from Cerastes cerastes venom which interact with the parasites. Toxicon, Vol. 32 (8):875-882.

Fetterer, R. y M. Rhoads. 1993. Biochemistry of the nematode cuticle: relevance to parasitic nematodes of livestock. Vet-Parasitol. Feb 46(1-4): 103-111.

García, L., 1989. Acción antihelmíntica de algunas monocotiledóneas y dicotiledóneas en el tratamiento de Trichuris muris implantados en ratones de la cepa swiss. Tesis para optar el grado de Magister en Biología. UPCH, Lima, Perú. pp. 3-5.

Juris, P.; P. Plachy y A. Laukova. 1995. Devitalization of bacterial and parasitic germs in sewage sludge during aerobic digestion under laboratory conditions. Vet-Med-Praha. May; 


\section{0(5): $157-62$}

Kunert, j. 1992. On the mechanism of penetration of ovicidal fungi through egg shells of parasitic nematodes. Decomposition of chitinous and ascaroside layers. Folia-Parasitol-Praha. 1992; 39(1):61-6.

Leńmensick, R., 1960. Nuestro Ascaride (Ascaris lumbricoides, Linne 1758) Symposium Ciba, 8: 2 , pp. 56-58.

Lumbreras, H y C. Náquira. 1985. A scaris lumbricoides infections in Perú. in: CROMPTON D., NESHEIN, M., PAWLOWSKY (Ed.) Ascaris and its public health significance. Edit. Taylor \& Francis. London and Philadejphia.

Massara, C.; H. De Araújo y D. CARVALHO. 1991. Viability of Ascaris lumbricoides eggs eliminated after antihelmintic therapy. Mem. Inst. Oswaldo Cruz, Río de Janeiro. 86(2):233-237.

Miranda, H., 1961. Evolución intrauterina de los huevos de Ascaris lumbricoides y estudio de su viabilidad en altas concentraciones formol.
Arch. Peruanos Pat. Clin. Vol. XV, pp. 95106.

Miranda, R. 1978. "Infección experrimental de Ascaris suum en ratones albinos". Trabajo práctico para optar el grado académico de Bachiller en Ciencias Biológicas. UPCH, Lima, Perú.

OMS, 1967. «Lucha Contra la Ascariasis». Serie de informes técnicos $\mathrm{N}^{\circ} 379$. Ginebra.

Rogers, R., 1956. A study of eggs of Ascaris lumbricoides var. suum with the electron microscope. J. Parasitol..42(2):97-108.

Schmidt, G y L. Roberts. 1984. Fundamentos de Parasitología. Edit. Continental. México D. F., pp 495-506.

Skames, R.C., 1970. L. amino oxidase, a bactericidal system. Nature 225, pp. 1072-1073.

Stiles, B.; F. Sexton y S. Wenstein. 1991. Antibacterial effects of diferent snake venoms; purification and characterization of antibacterial proteins from Pseudechis australis (Australian King Brown or Mulga snake) Venom. Toxicon. 29(9): 1129-1141.

Yarlequé, A.; J. Cardenas; E. Escobar y S. Gutierrez. 1996. Some biochemical properties and antibacterial action of a L-aminoacid oxidase from Peruvian snake venoms. Toxicon. Vo]. 35, $\mathrm{N}^{0} 4$, pp 489. Kunning. Yunnan. China. 